\title{
Diffractive and Interferometric Characterization of Nanostructured Photopolymer for Sharp Diffractive Optical Elements Recording
}

\author{
Roberto Fernández $^{1, *}$, Sergi Gallego ${ }^{1,2}$ (D), Yasuo Tomita ${ }^{3}$, Inmaculada Pascual ${ }^{1,4}$ (1) \\ and Augusto Beléndez 1,2 (iD) \\ 1 Instituto Universitario de Física Aplicada a las Ciencias y las Tecnologías, Universidad de Alicante, P.O. Box \\ 99, E-03080 Alicante, Spain; sergi.gallego@ua.es (S.G.); pascual@ua.es (I.P.); a.belendez@ua.es (A.B.) \\ 2 Departamento de Física, Ingeniería de Sistemas y Teoría de la Señal, Universidad de Alicante, P.O. Box 99, \\ E-03080 Alicante, Spain \\ 3 Department of Engineering Science, University of Electro-Communications, 1-5-1 Chofugaoka, Chofu, \\ Tokyo 182-8585, Japan; ytomita@ee.uec.ac.jp \\ 4 Departamento de Óptica, Farmacología y Anatomía, Universidad de Alicante, P.O. Box 99, \\ E-03080 Alicante, Spain \\ * Correspondence: roberto.fernandez@ua.es; Tel.: +34-965-903-464
}

Received: 9 April 2018; Accepted: 8 May 2018; Published: 10 May 2018

\begin{abstract}
We study the behavior of a nanoparticle-polymer composite (NPC) material, based on a thiol-ene monomer system, working with long grating spacing. Thus, we evaluate the suitability of the NPC for storing complex diffractive optical elements with sharp profiles, such as blazed gratings. Using holographic methods, we measure the "apparent" diffusion of the material and the influence of the spatial period on this diffusion. The applicability of this material in complex diffractive optical elements (DOEs) recording is analyzed using an interferometric method. Supported by the results of this analysis, we record blazed gratings with different grating spacing and measure the maximum diffraction efficiency (DE) achieved. The results show that NPC has a good behavior in this range of spatial frequencies.
\end{abstract}

Keywords: photopolymers; optical recording material; diffractive optical element; nanoparticlepolymer composite; nanoparticles

\section{Introduction}

Photopolymerizable nanoparticle-polymer composites (NPCs) are a holographic dry composition in which inorganic nanoparticles, such as $\mathrm{TiO}_{2}, \mathrm{SiO}_{2}, \mathrm{ZrO}_{2}$, nanozeolites [1-5], and organic nanoparticles [6], are uniformly dispersed in organic host monomers that are capable of chain-growth polymerization. During the polymerization process, a light-induced redistribution of the monomer and nanoparticles takes place in the bright and dark regions of the light pattern, respectively. This is due to the mutual diffusion process of the monomer and nanoparticles driven by the polymerization process $[1,7,8]$.

The inclusion of inorganic nanoparticles, which have a higher refractive index than that of the formed polymer, leads to important improvements in refractive index modulation. Other improvements include the suppression of polymerization shrinkage and a high thermal stability [1,2,9]. Such improvements may be combined by the incorporation of liquid crystal molecules into an NPC material for electro-optic control [10-12] of the formed holographic grating recorded in the NPC material.

In previous work [13], we explored the electro-optic capabilities of a holographic polymer dispersed liquid crystal (HPDLC) in working with low spatial frequencies. 
We found that it was difficult to increase the refractive modulation amplitude due to its large monomer diffusivity, and also to reduce polymerization shrinkage during recording for the realization of low spatial frequency diffractive optical elements (DOEs) with sharp profiles. For this reason, we investigate the electro-optic characteristics of DOEs recorded in the NPC material incorporated with liquid crystals in the low spatial frequency regime. Along this line, our present work examines the holographic recording properties of NPC gratings possessing large grating spacing (low spatial frequencies).

For holographic recording, the high performances of NPCs based on thiol-ene/thiol-yne photopolymerization have been demonstrated and the recording dynamics have been analyzed in detail [14-17]. Further, new chemistry systems and formulations for thiol-ene systems have been developed. Recently, Bowman et al. proposed thiol-X click chemistry, with simple processability and environmental friendliness [18], and a 1,3-bis(phenylthio)-2-propyl acrylate (BPTPA) monomer, a writing monomer capable of reaching a refractive index modulation up to 0.029 [19]. In this work, we carry out a novel analysis of the recording dynamics of thiol-ene-based NPC gratings at low spatial frequencies, for which we follow the same procedure as those previously used for other families of photopolymers, such as polyvinyl alcohol acrylamide (PVA/AA) based photopolymers, one of the most widely-studied photopolymers due to its good characteristics [20-22], Biophotopol [22,23], or HPDLC $[13,22]$. PVA/AA and Biophotopol materials have also demonstrated good results working with complex DOEs, obtaining good results from the material and high diffraction efficiencies (DEs). These values were near to their maximum, if we consider the losses introduced by the setup, which will be commented on below. Therefore, it is interesting to use PVA/AA, Biophotopol and HPDLC as a reference to compare to the NPC material for these applications. The results of this study show the suitability of the NPC material to work, not only in a holographic regime, but also to store many complex DOEs, such as blazed gratings [24] or diffractive lenses [25]. We start with a post-exposure evolution analysis to measure the monomer's "dark" diffusion after a short recording exposure. In the post-exposure process, there is no polymerization and only the monomer's diffusion is responsible for changes in the profile. Post-exposure evolution analysis is also performed to investigate whether or not monomer dark diffusion depends on grating spacing, extending the analysis to different spatial period gratings. Moreover, using the zero-frequency analysis method [26], we can complete the material's characterization. In this zero-frequency limit, we avoid the monomer's diffusion effects and directly measure different parameters, such as the polymerization rate $\left(F_{R}\right)[27,28]$. Through the zero-frequency analysis method, we study the capabilities of the NPC material to reach a phase depth of $2 \pi$. This is an important point because this phase depth is required for complex DOEs. Furthermore, we perform a recording of a complex element, a blazed grating, in the NPC material. This is done by using a liquid crystal on a silicon (LCOS) microdisplay based spatial light modulator (model PLUTO, Holoeye, Berlin, Germany), which is turned into a phase element once projected on the NPC material.

\section{Experimental Setup}

Our NPC monomer system was composed of a stoichiometric mixture of thiol-ene monomer, containing an allyl-triazine-ene monomer, triallyl-1,3,5-triazine-2,4,6 $(1 \mathrm{H}, 3 \mathrm{H}, 5 \mathrm{H}$ )-trione (Aldrich, St. Louis, MI, USA), and a dithiol monomer, 1,4-bis(3-mercaptobutyryloxy)butane (Showa Denko K.K., Tokyo, Japan), of which the chemical structures are shown in Figure 1a,b. Ten- to fifteen-nanometer $\mathrm{SiO}_{2}$ nanoparticles, dispersed in methyl isobutyl ketone (MIBK, Nissan Chemical Industries Ltd., Tokyo, Japan) at a concentration of $30 \mathrm{wt} \%$ were dispersed to the thiol-ene monomer blend. Transmission electron microscopy (TEM) images of the nanoparticles, at 10 and $20 \mathrm{~nm}$, are shown in Figure 2a,b respectively. The refractive index difference between $\mathrm{SiO}_{2}$ nanoparticles and the formed thiol-ene polymer was close to 0.1 , which helps to obtain large values of the refractive index modulation. The use of nanoparticles also improves the thermal stability of the gratings recorded in the NPC material, as mentioned earlier [9]. The efficient polymerization of the NPC material using a green laser was achieved by the addition of $2 \mathrm{wt} \%$ of titanocene organo-metallic complex (Chivacure 534, 
Chitec, Taibei, Taiwan) in combination with $2.5 \mathrm{wt} \%$ benzoyl peroxide $\left(\mathrm{BzO}_{2}\right.$, Aldrich, St. Louis, MI, USA) [14-16].<smiles>CC(S)CC(=O)OCCCCOC(=O)CC(C)S</smiles>

a) b)<smiles>C=CCn1c(=O)n(CC=C)c(=O)n(CC=C)c1=O</smiles>

Figure 1. Chemical structures of dithiol (a) and triallyl (b) monomers.
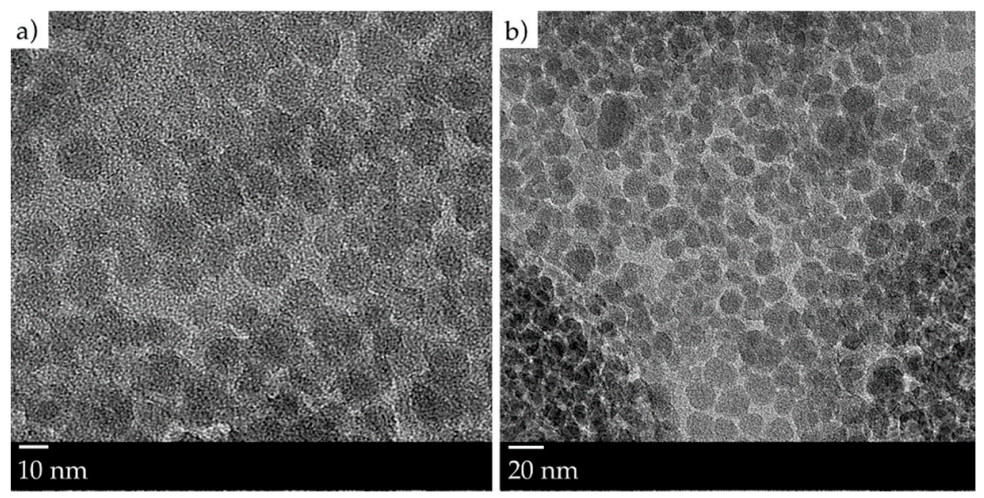

Figure 2. TEM images of $\mathrm{SiO}_{2}$ nanoparticles in MIBK at $10 \mathrm{~nm}(\mathbf{a})$ and at $20 \mathrm{~nm}$ (b).

The mixed syrup was dropped onto a glass substrate and dried in an oven at $55^{\circ} \mathrm{C}$ for $20 \mathrm{~min}$ to eliminate the MIBK solvent. Then, another glass substrate was placed to cover the syrup. We used 20-30 $\mu \mathrm{m}$ glass microspheres (White Scientific) as spacers between the two glass substrates. Figure 3 shows SEM images of a blazed grating of $672 \mu \mathrm{m}$, recorded in 30- $\mu \mathrm{m}$ thickness NPC material. These images were taken from uncovered material. We made the material used between the glass substrate and the cover slip and removed the glass substrate after recording. In the removal process, the grating was slightly stretched, as seen in Figure 3. In this figure, the glass microspheres, used as spacers, can be observed at the sides of the grating.

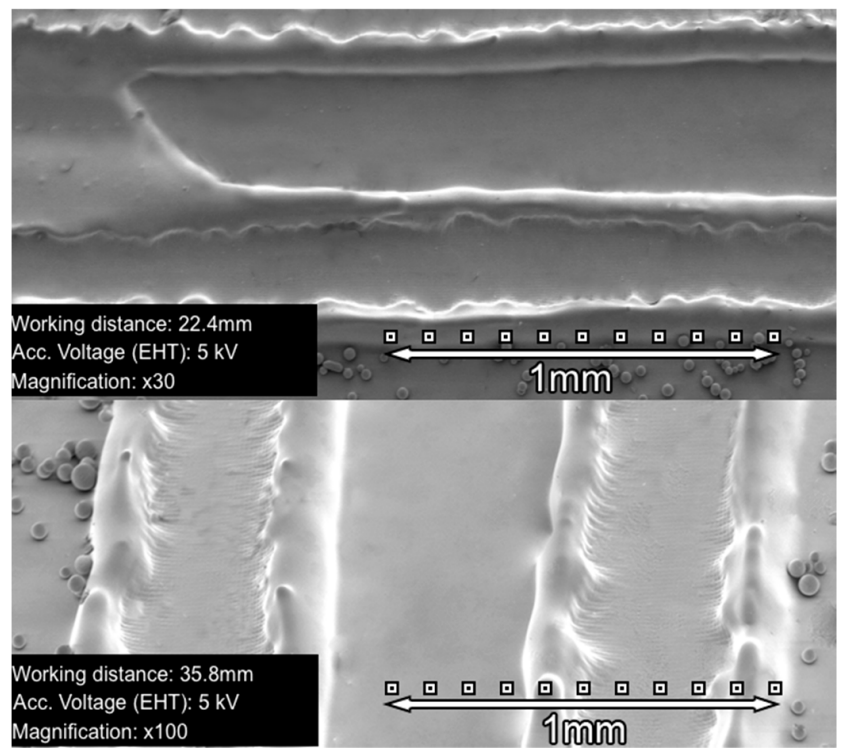

Figure 3. SEM images of a $672 \mu \mathrm{m}$ blazed grating recorded in a $30-\mu \mathrm{m}$ thickness NPC material. 
To record and evaluate the DOEs in the NPC material, we used the setup shown in Figure 4, which consisted of two beams. The recording green beam was formed using a solid-state laser (model Verdi Nd: $\mathrm{YVO}_{4}$, Coherent, CA, USA), operating at a wavelength of $532 \mathrm{~nm}$ (green light). The DOE pattern was introduced by the LCoS spatial light modulator (SLM), which was located on the recording arm. Amplitude modulation was produced using the two polarizers (LPs) placed on both sides of the device. Then, to image the intensity distribution generated by the SLM onto the recording material, we used a $4 \mathrm{f}$ system, which gives direct access to the Fourier plane. Two identical lenses (L3, L4) had a common focal point, where a diaphragm (D3) was placed. Thus, the distance between input plane and image plane was 4 times the length of $\mathrm{f}$ [29]. We measured DEs in real time, defined as:

$$
\mathrm{DE}=\frac{I_{\mathrm{i}}}{I_{\mathrm{I}}}
$$

where $I_{\mathrm{i}}$ is the intensity of the diffraction orders and $I_{\mathrm{I}}$ is the incident intensity.

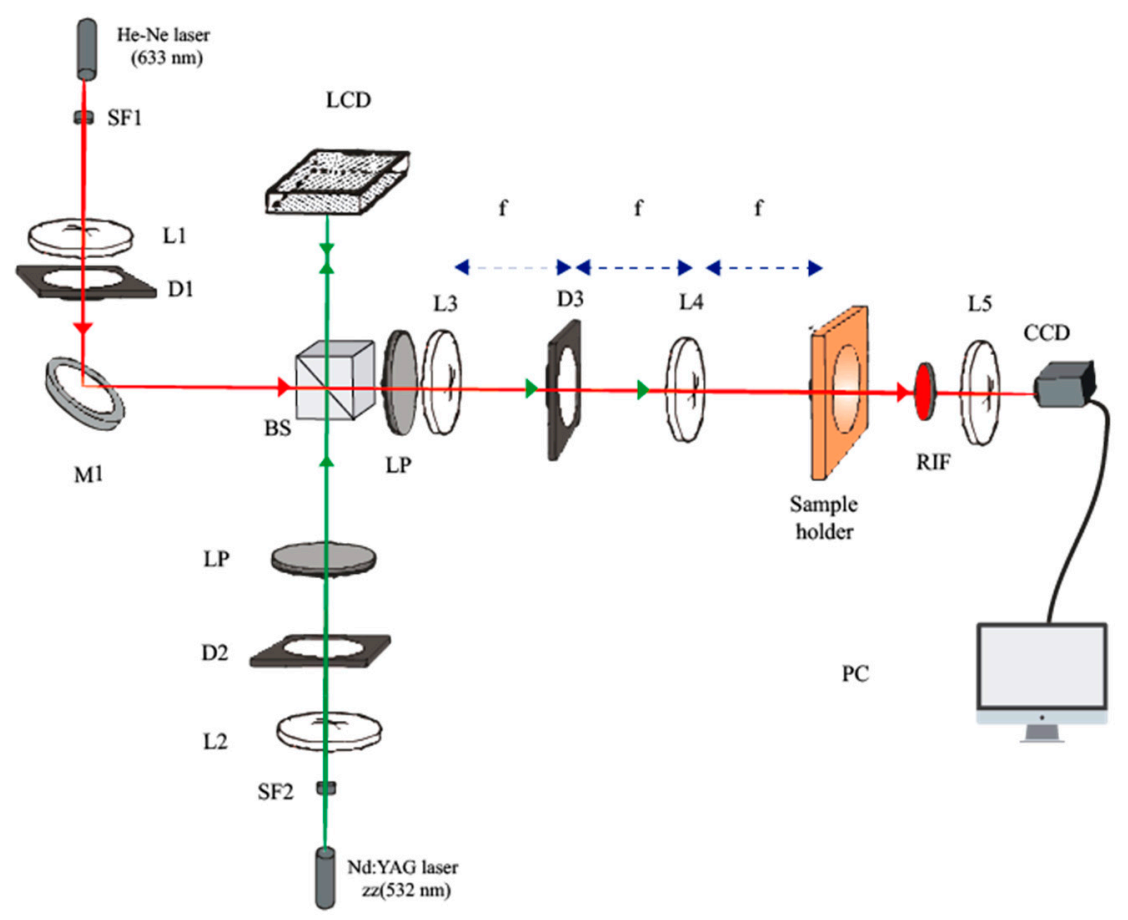

Figure 4. Experimental setup. BS: beam splitter, Mi: mirror, SFi: spatial filter, LP: lineal polarizer, Li: lens, Di: diaphragm, RIF: red interference filter and PC: data recorder.

The system was made up of two beams. An s-polarized He-Ne laser operating at a wavelength of $633 \mathrm{~nm}$, where the NPC material had no light absorption, was used to analyze changes due to the photopolymerization in real-time. This beam was collimated before it reached the NPC material and its aperture was controlled using a diaphragm (D1). Both beams passed through a non-polarizing beam splitter (BS), following the same path. Behind the NPC material, there was a red interference filter (RIF) so that only the information from the red beam, the analyzing beam, was captured on a high dynamic range CCD camera (model pco.1600, pco.imaging, Kelheim, Germany), which was located at the end of the setup, at a resolution of $1600 \times 1200$ and a pixel size of $7.4 \mu \mathrm{m} \times 7.4 \mu \mathrm{m}$. In front of the CCD camera a lens (L5) was used to separate the diffraction behind the material and obtain the Fraunhofer diffraction pattern. The intensity pattern to be recorded into the NPC material was also evaluated, using the CCD camera to record the pattern imaged by the SLM plane. The recording intensity used was $0.2 \mathrm{~mW} / \mathrm{cm}^{2}$. 


\section{Results and Discussion}

In this section we present various experimental results for the DE achieved with the NPC material. The different experiments carried out were described in the Introduction. As DEs of different diffracted orders in the Fraunhofer domain are given by the Bessel functions [30], a comparison of the theoretical DEs with those measured experimentally gives the linearity in the response of the NPC material. The results are discussed in comparison to those obtained for PVA/AA, Biophotopol and HPDLC materials.

\subsection{Post-Exposure Evolution}

In this section, we will discuss the post-exposure evolution of the NPC material. Following the method proposed in Reference [27], we can fit the value of the apparent monomer diffusion. Due to the confinement of the NPC material between two glass substrates, we cannot measure separately the changes in the surface and the internal changes through an index matching system, as we did previously for PVA/AA and Biophotopol based materials.

We exposed a $30-\mu \mathrm{m}$ in thickness layer to a $168-\mu \mathrm{m}$ sinusoidal grating during different exposure times of 50, 100 and $150 \mathrm{~s}$, then switched off the recording green laser and studied the evolution of the NPC material. Then, following the method applied in Reference [28], we calculated the value of diffusivity through fitting using the following relation:

$$
\ln (\mathrm{PS}(\mathrm{x}, \mathrm{t} \rightarrow \infty)-\mathrm{PS}(\mathrm{x}, \mathrm{t}))=\ln (\mathrm{PS}(\mathrm{x}, \mathrm{t} \rightarrow \infty))-\frac{D \cdot 4 \pi^{2} \cdot t}{\Lambda^{2}}
$$

where PS is the phase shift, $\mathrm{PS}(\mathrm{x}, \mathrm{t} \rightarrow \infty)$ is the phase shift for long times when the grating becomes stable, $D$ is "apparent" diffusion, and $\Lambda$ represents the grating period. In this case, after recording, the DE of the zero and first order remained practically constant. Figure $5 \mathrm{a}$ shows the post-exposure evolution of the material after 50,100,150,350, and $400 \mathrm{~s}$ of exposure. The fitting for the grating, stopped after $150 \mathrm{~s}$ of exposure time to obtain the diffusivity value, and is shown in Figure 6. The diffusivity values measured were $(2 \pm 1) \times 10^{-9} \mathrm{~cm}^{2} / \mathrm{s}$, which are higher than those measured for the PVA/samples with index matching system [21], but much lower when compared with samples without the index matching system, in which values around $1^{-8} \mathrm{~cm}^{2} / \mathrm{s}$ were obtained [21,31]. As the experiments were conducted several times, the error estimated $\left( \pm 1 \times 10^{-9} \mathrm{~cm}^{2} / \mathrm{s}\right)$ was due to the repeatability and the existing ambiguity when determining the $\operatorname{PS}(x, t \rightarrow \infty)$.

a)

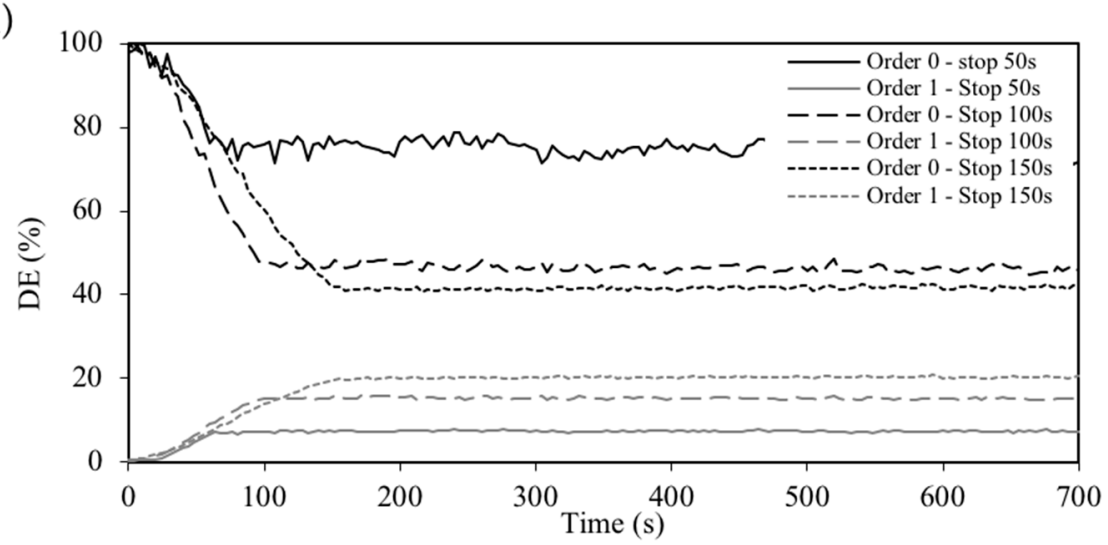

Figure 5. Cont. 
b)

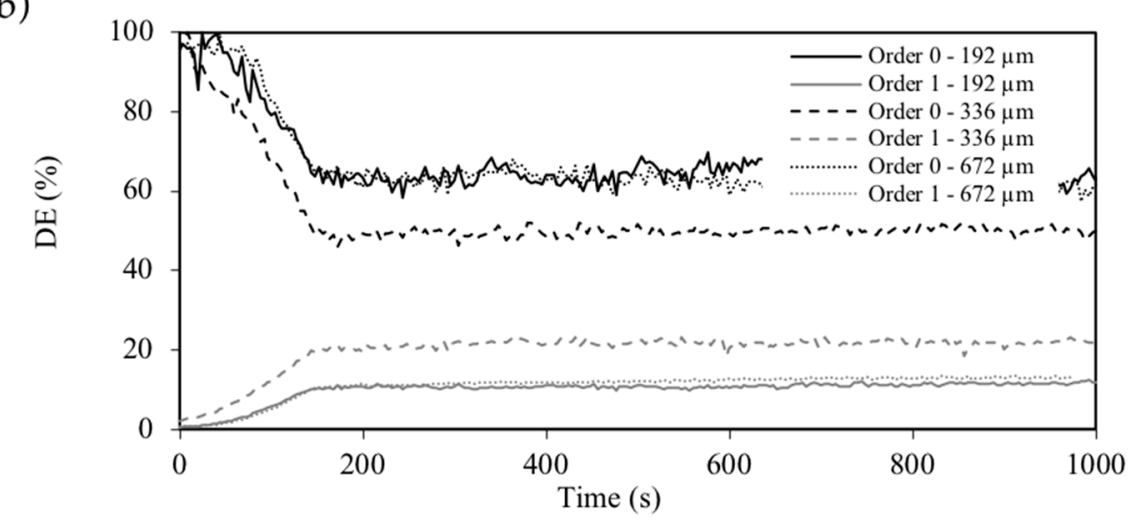

Figure 5. (a) DE of zero and first orders as a function of time for an exposure of a $720 \mu \mathrm{m}$ sinusoidal grating over 50,100 and $150 \mathrm{~s}$ and the post-evolution. (b) DE of zero and first orders as a function of time for an exposure of 192, 336 and $672 \mu \mathrm{m}$ sinusoidal gratings during $150 \mathrm{~s}$ and the post-evolution.

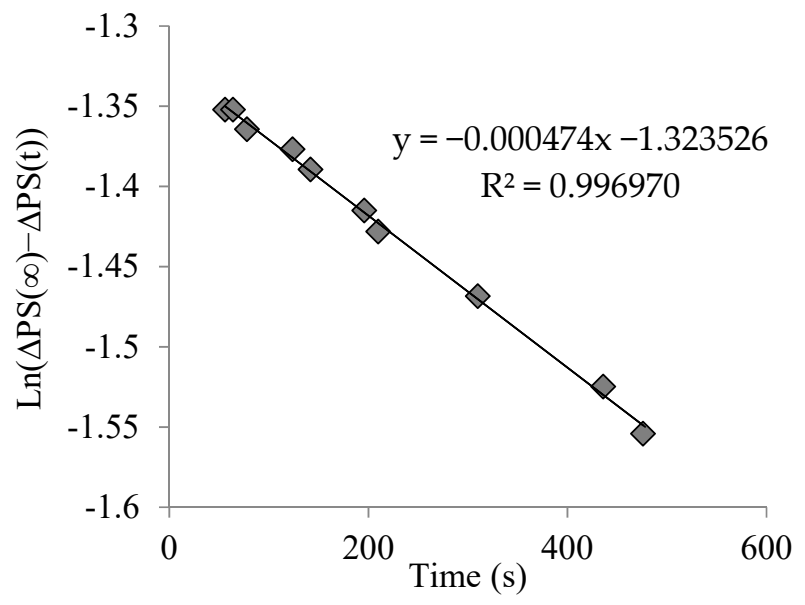

Figure 6. Fitting to obtain diffusivity value for an exposure time value of $150 \mathrm{~s}$.

We also studied the influence of grating spacing on apparent diffusion, because an increase of grating spacing may increase the apparent diffusion rate [16]. This is not desirable when working with DOEs composed by different spatial periods, such as diffractive lenses [25]. Figure $5 b$ shows the post exposure evolution of 192, 336, and $672 \mu \mathrm{m}$ sinusoidal gratings, recorded over $150 \mathrm{~s}$ and their post-exposure evolutions. In this case, the diffusivity values measured were near those previously measured: $(2 \pm 1) \times$ $10^{-9} \mathrm{~cm}^{2} / \mathrm{s}$ at grating spacings of 192 and $336 \mu \mathrm{m}$, and $(8 \pm 1) \times 10^{-9} \mathrm{~cm}^{2} / \mathrm{s}$ at a grating spacing of $672 \mu \mathrm{m}$. Therefore, we found that there was no strong influence of grating spacing on the apparent diffusion.

\subsection{Phase Shift and Diffraction Efficency}

The analysis of the recording of blazed gratings in PVA/AA, Biophotopol and HPDLC materials $[13,24]$ was carried out in previous research. Blazed grating is a complex DOE, which presents a sharp profile with abrupt changes. This profile has many applications in communications and a theoretical maximum DE near $100 \%$.

Firstly, to see the capabilities of the material to reach a phase depth of $2 \pi$, we used zero spatial frequency analysis $[20,32]$. We illuminated an area $\left(1 \mathrm{~cm}^{2}\right)$ and, using an interferometric method, we measured the phase shift (PS) between the exposed and non-exposed zones as a function of time without the influence of diffusion. In References [33,34], $F_{R}$ has been studied and simulated for thiol-ene systems. In our case, the polymerization rate depended on the photon dose, the recording intensity, and the fraction of light absorbed by the photoinitiator. Following the procedure developed 
in Reference [20], we obtained $F_{R}$ as a function of the experimental values of PS during recording and the phase of saturation $\left(\mathrm{PS}_{\infty}\right)$ :

$$
\ln \left(1-\frac{\mathrm{PS}(\mathrm{t})}{\mathrm{PS}_{\infty}}\right)=-F_{\mathrm{R}} \cdot \mathrm{t}
$$

Figure 7 shows the phase shift as a function of exposure time for a 30- $\mu \mathrm{m}$ thickness sample using an intensity of $0.2 \mathrm{~mW} / \mathrm{cm}^{2}$. As seen in Figure 7, the phase shift between the exposed and non-exposed zones was near $450^{\circ}$ over the $2 \pi$ needed for complex DOEs recording. The maximum phase shift was reached after $1000 \mathrm{~s}$ of exposure time; this long exposure means that the polymerization time of the NPC material was significantly slower than the reaction time of other analyzed materials, such as AA/PVA, Biophotopol, or HPDLC, where all the monomer is consumed after 100 or $200 \mathrm{~s}$ with the same intensity. This can be due to the significantly lower absorbance at the recording wavelength of the NPC material [15] compared to the recording wavelength of the other families of materials analyzed [23,35], causing this slower reaction time. Figure 8 shows the fitting of Equation (3) to obtain the value of $F_{R}$. The value obtained for this polymerization rate was $2.9 \times 10^{-3} \mathrm{~s}^{-1}$. It is also worth mentioning the high correlation value of the fitting, which indicates a good agreement between theory and experimental results.

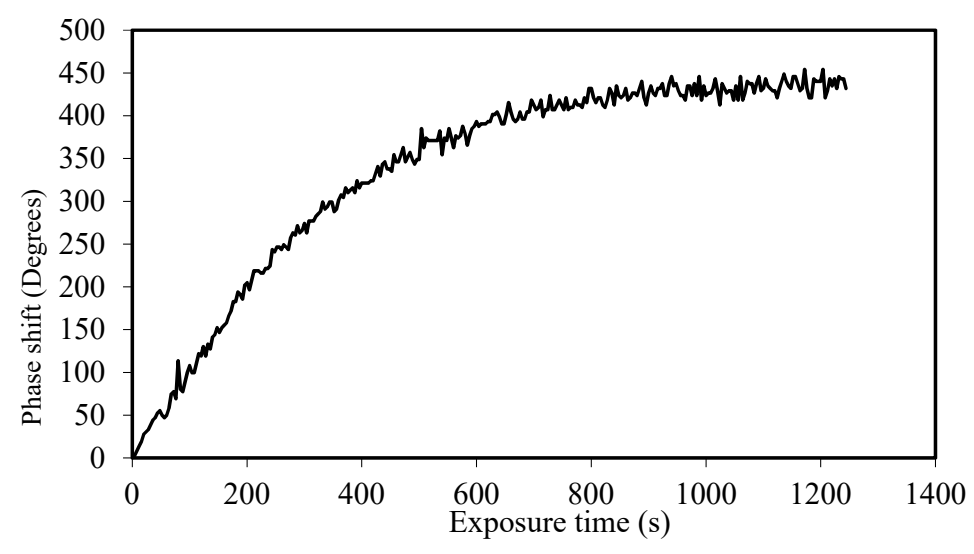

Figure 7. Phase shift as a function of exposure time for a $30-\mu \mathrm{m}$ thickness material.

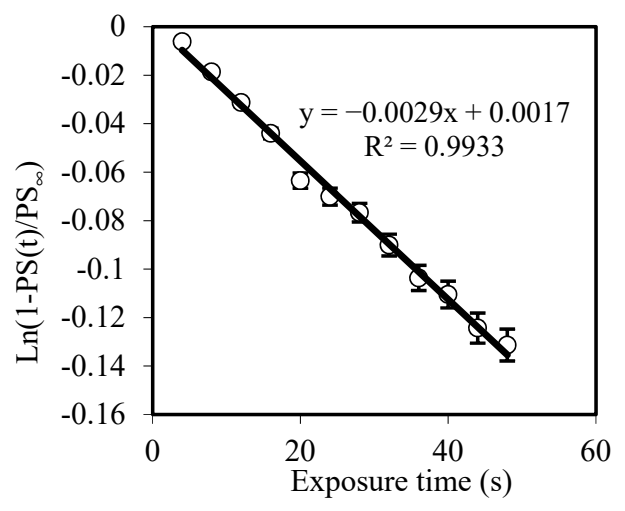

Figure 8. Fitting derived from Equation (3) to extract the value of polymerization rate $\left(F_{R}\right)$.

Since the material exhibited the capability of reaching a $2 \pi$ phase shift for $30-\mu \mathrm{m}$ thickness samples, we proceeded to analyze the recording of blazed gratings. First, we used the CCD camera to evaluate the intensity pattern imaged from the plane of the modulator. Figure 9 shows the intensity distribution provided by LCOS across a vertical line, compared to the theoretical one. The experimental intensity distribution was extracted from a vertical line of the image of a $720 \mu \mathrm{m}$ period grating, recorded by the CCD camera. It is noticeable that the experimental intensity distribution presents a smoothing of abrupt edges, due to the low pass filtering introduced by the setup. 


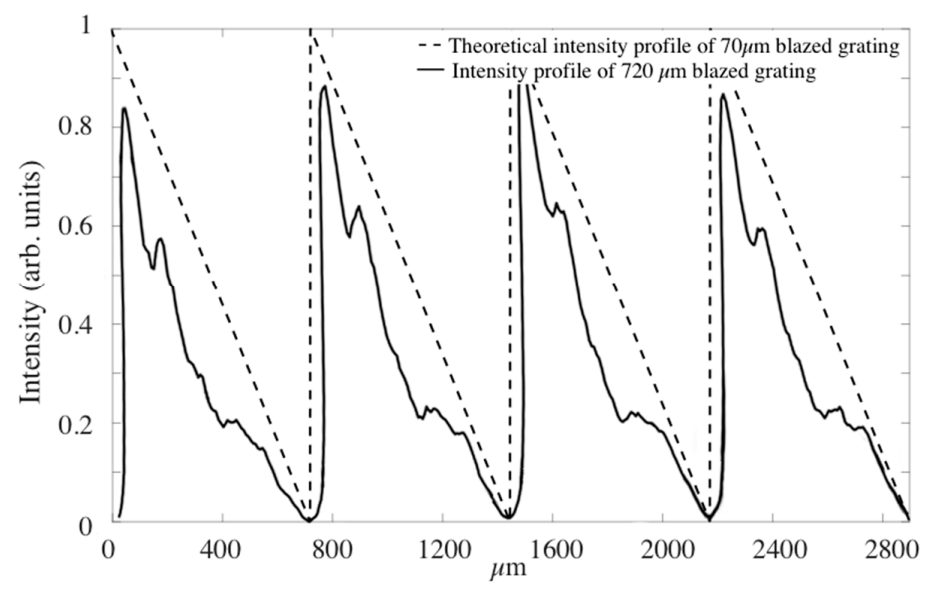

Figure 9. Intensity profile provided by the LCoS across a vertical line of the image recorded using the CCD camera on the material plane and theoretical profile of blazed grating.

We recorded gratings of different spatial periods in 30- $\mu \mathrm{m}$ samples and checked the DE as a function of exposure time. Figure 10a-c shows DE as a function of time for 720, 336, and $168 \mu \mathrm{m}$ gratings, respectively, using a recording intensity of $0.2 \mathrm{~mW} / \mathrm{cm}^{2}$. The maximum value of $\mathrm{DE}$ was obtained for the $720-\mu \mathrm{m}$ blazed grating, which reached close to $65 \%$ of $\mathrm{DE}$ after $500 \mathrm{~s}$ of exposure. This value is near the maximum achievable by the material, accounting for the low pass filtering which reduces the maximum DE obtainable by more than $20 \%$ [24]. In this case, the reaction time shown by the NPC material was slower compared to the other materials studied (PVA/AA based material, Biophotopol, HPDLC).
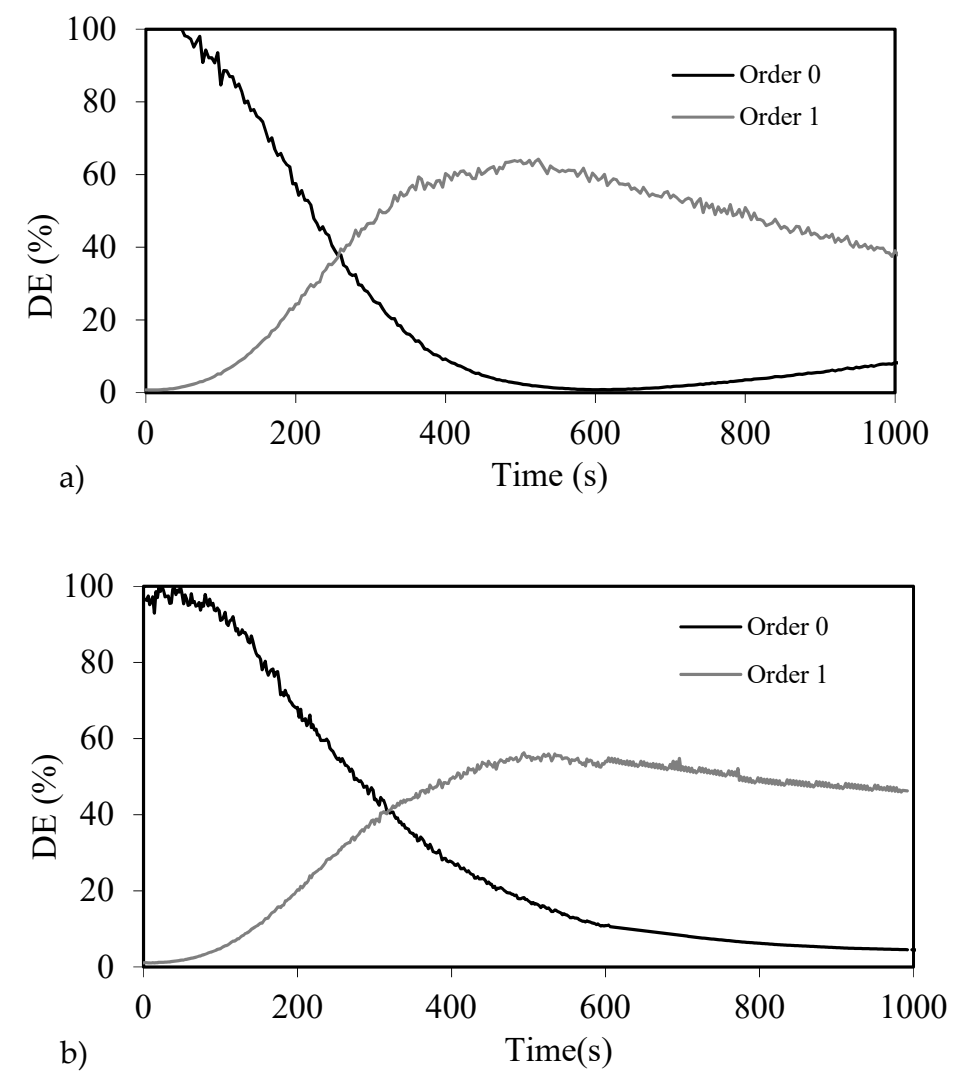

Figure 10. Cont. 


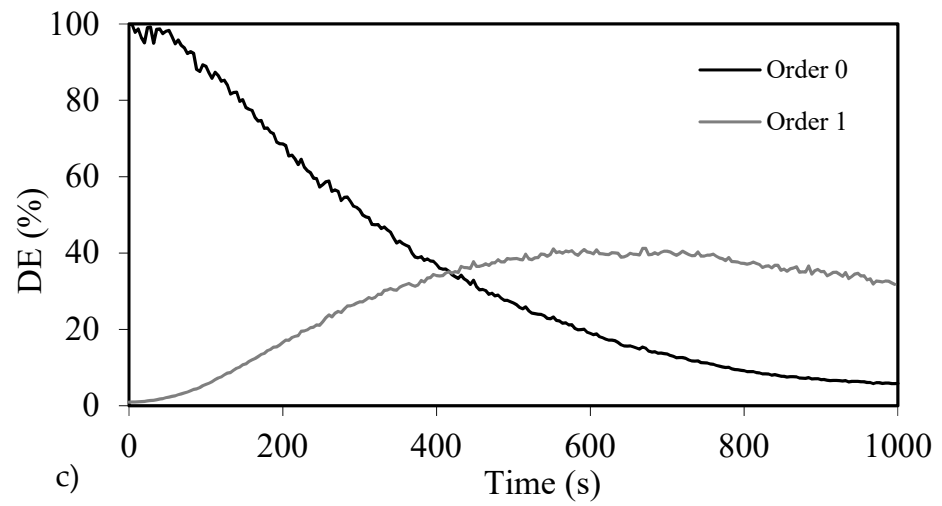

Figure 10. Diffraction efficiency of zero and first orders as a function of time for $720 \mu \mathrm{m}(\mathbf{a}), 336 \mu \mathrm{m}(\mathbf{b})$ and $168 \mu \mathrm{m}$ (c) blazed gratings recorded onto NPC material.

The effects of the diffusion are stronger for shorter grating spacings, as well as the effect of the low pass filtering commented above. These effects are noticeable in the maximum DE obtained, which was lower for smaller spatial periods, near $55 \%$ for the $336 \mu \mathrm{m}$ grating and $40 \%$ for the $168 \mu \mathrm{m}$ grating. This diffusion was also affected by the viscosity of the material, which depends on the drying conditions and modifies the diffusion coefficient, as demonstrated previously for different photopolymers and grating periods [36]. However, these DEs results are good, considering that due to the low pass filtering it is not possible to reach the $100 \%$ of theoretical DE.

\section{Conclusions}

We analyzed the behavior of an NPC material working with long grating spacing (low spatial frequencies) and its suitability to store complex DOEs, such as blazed gratings. We have found that the value measured for the diffusion of the material, $(2 \pm 1) \times 10^{-9} \mathrm{~cm}^{2} / \mathrm{s}$, is significantly lower than those measured for materials without using the index matching system. We have also verified that the grating spacing does not have a strong influence on the diffusion, because we have obtained similar values of diffusivity for three different grating spacings.

This study was completed with a zero-frequency limit analysis, without diffusion effects, which showed the capability of the NPC material to reach a phase depth higher than $2 \pi$. This analysis also permitted us to fit the value of the polymerization rate, $2.9 \times 10^{-3} \mathrm{~s}^{-1}$.

Supported by the phase depth value obtained, we recorded blazed gratings of various grating spacing. We obtained a maximum DE of $65 \%$ for the $720 \mu \mathrm{m}$ grating, near the maximum achievable given the low pass filtering introduced by the setup. This first approach has shown the good behavior of the NPC material and set it up as a good candidate for this range of spatial frequencies, keeping open the possibility of continued research with the NPC material in this range.

Author Contributions: R.F. performed the experiments and wrote the paper, S.G designed the diffusion model and simulated the material behavior. Y.T designed and optimized the material composition and supervised the paper, A.B and I.P conceived and designed the experiments and prepared the experimental setup.

Acknowledgments: This work was supported by the "Ministerio de Economía Industria y Competitividad" (Spain) under projects FIS2017-82919-R (MINECO/AEI/FEDER, UE) and FIS2015-66570-P (MINECO/FEDER). and by "Generalitat Valenciana" (Spain) (PROMETEOII/2015/015). Some of the authors, R.F. and Y.T., acknowledge financial support by the Ministry of Education, Culture, Sports, Science and Technology of Japan under grant $15 \mathrm{H} 03576$.

Conflicts of Interest: The authors declare no conflicts of interest. 


\section{References}

1. Tomita, Y.; Hata, E.; Momose, K.; Takayama, S.; Liu, X.; Chikama, K.; Klepp, J.; Pruner, C.; Fally, M. Photopolymerizable nanocomposite photonic materials and their holographic applications in light and neutron optics. J. Mod. Opt. 2016, 63, S1-S31. [CrossRef] [PubMed]

2. Suzuki, N.; Tomita, Y. Holographic recording in $\mathrm{TiO}_{2}$ nanoparticle-dispersed methacrylate photopolymer films. Appl. Phys. Lett. 2002, 81, 4121-4123. [CrossRef]

3. Sakhno, O.V.; Goldenberg, L.M.; Stumpe, J.; Smirnova, T.T. Surface modified $\mathrm{ZrO}_{2}$ and $\mathrm{TiO}_{2}$ nanoparticles embedded in organic photopolymers for highly effective and UV-stable volume holograms. Nanotechnology 2007, 18, 105704. [CrossRef]

4. Kim, W.S.; Jeong, Y.-C.; Park, J. Nanoparticle-induced refractive index modulation of organic-inorganic hybrid photopolymer. Opt. Express 2006, 14, 8967-8973. [CrossRef] [PubMed]

5. Moothanchery, M.; Naydenova, I.; Mintova, S.; Toal, V. Nanozeolites doped photopolymer layers with reduced shrinkage. Opt. Express 2011, 19, 25786-25791. [CrossRef] [PubMed]

6. Tomita, Y.; Furushima, K.; Ochi, K.; Ishizu, K.; Tanaka, A.; Ozawa, M.; Hidaka, M.; Chikama, K. Organic nanoparticle (hyperbranched polymer)-dispersed photopolymers for volume holographic storage. Appl. Phys. Lett. 2006, 88, 071103. [CrossRef]

7. Chikama, K.; Mastubara, K.; Oyama, S.; Tomita, Y. Three-dimensional confocal Raman imaging of volume holograms formed in $\mathrm{ZrO}_{2}$ nanoparticle-photopolymer composite materials. J. Appl. Phys. 2005, 103, 113108. [CrossRef]

8. Kalathi, J.T.; Yamamoto, U.; Schweizer, K.S.; Grest, G.S.; Kumar, S.K. Nanoparticle diffusion in polymer nanocomposites. Phys. Rev. Lett. 2014, 112, 108301. [CrossRef] [PubMed]

9. Tomita, Y.; Nakamura, T.; Tago, A. Improved thermal stability of volume holograms recorded in nanoparticle-polymer composite films. Opt. Lett. 2008, 33, 1750-1752. [CrossRef] [PubMed]

10. Li, M.S.; Fuh, A.Y.-G.; Liu, J.-H.; Wu, S.-T. Bichromatic optical switch of diffractive light from a BCT photonic crystal based on an azo component-doped HPDLC. Opt. Express 2012, 20, 25545-25553. [CrossRef] [PubMed]

11. Ren, H.; Fan, Y.-H.; Lin, Y.-H.; Wu, S.-T. Tunable-focus microlens arrays using nanosized polymer-dispersed liquid crystal droplets. Opt. Commun. 2005, 247, 101-106. [CrossRef]

12. Li, M.S.; Wu, S.T.; Fuh, A.Y.G. Sensor for monitoring the vibration of a laser beam based on holographic polymer dispersed liquid crystal films. Opt. Express 2010, 18, 26300-26306. [CrossRef] [PubMed]

13. Fernández, R.; Gallego, S.; Márquez, A.; Francés, J.; Martínez, F.J.; Pascual, I.; Beléndez, A. Analysis of holographic polymer-dispersed liquid crystals (HPDLCs) for tunable low frequency diffractive optical elements recording. Opt. Mater. 2018, 76, 295-301. [CrossRef]

14. Hata, E.; Tomita, Y. Order-of-magnitude polymerization-shrinkage suppression of volume gratings recorded in nanoparticle-polymer composites. Opt. Lett. 2010, 35, 396-398. [CrossRef] [PubMed]

15. Hata, E.; Mitsube, K.; Momose, K.; Tomita, Y. Holographic nanoparticle-polymer composites based on step-growth thiol-ene photopolymerization. Opt. Mater. Express 2011, 1, 207-222. [CrossRef]

16. Hata, E.; Tomita, Y. Stoichiometric thiol-to-ene ratio dependences of refractive index modulation and shrinkage of volume gratings recorded in photopolymerizable nanoparticle-polymer composites based onstep-growth polymerization. Opt. Mater. Express 2011, 1, 1113-1120. [CrossRef]

17. Mitsube, K.; Nishimura, Y.; Nagaya, K.; Takayama, S.; Tomita, Y. Holographic nanoparticle-polymer composites based on radical-mediated thiol-yne photopolymerizations: Characterization and shift-multiplexed holographic digital data page storage. Opt. Mater. Express 2014, 4, 982-996. [CrossRef]

18. Peng, H.; Nair, D.P.; Kowalski, B.A.; Xi, W.; Gong, T.; Wang, C.; Cole, M.; Cramer, N.B.; Xie, X.; McLeod, R.R.; et al. High Performance Graded Rainbow Holograms via Two-Stage Sequential Orthogonal Thiol-Click Chemistry. Macromolecules 2014, 47, 2306-2315. [CrossRef]

19. Alim, M.D.; Glugla, D.J.; Mavila, S.; Wang, C.; Nystrom, P.D.; Sullivan, A.C.; McLeod, R.R.; Bowman, C.N. High Dynamic Range $(\Delta \mathrm{n})$ Two-Stage Photopolymers via Enhanced Solubility of a High Refractive Index Acrylate Writing Monomer. ACS Appl. Mater. Interfaces 2018, 10, 1217-1224. [CrossRef] [PubMed]

20. Gallego, S.; Márquez, A.; Martínez, F.J.; Riquelme, M.; Fernández, R.; Pascual, I.; Beléndez, A. Linearity in the response of photopolymers as optical recording media. Opt. Express 2013, 21, 10995-11008. [CrossRef] [PubMed] 
21. Fernández, R.; Gallego, S.; Márquez, A.; Francés, J.; Martínez, F.J.; Beléndez, A. Influence of index matching on AA/PVA photopolymers for low spatial frequency recording. Appl. Opt. 2015, 54, 3132-3140. [CrossRef] [PubMed]

22. Fernández, R.; Gallego, S.; Francés, J.; Pascual, I.; Beléndez, A. Characterization and comparison of different photopolymers for low spatial frequency recording. Opt. Mater. 2015, 44, 18-24. [CrossRef]

23. Ortuño, M.; Gallego, S.; Márquez, A.; Neipp, C.; Pascual, I.; Beléndez, A. Biophotopol: A Sustainable Photopolymer for Holographic Data Storage Applications. Materials 2012, 5, 772-783. [CrossRef] [PubMed]

24. Fernández, R.; Gallego, S.; Márquez, A.; Francés, J.; Navarro-Fuster, V.; Beléndez, A. Blazed gratings recorded in absorbent photopolymers. Materials 2016, 9, 195. [CrossRef] [PubMed]

25. Fernández, R.; Gallego, S.; Márquez, A.; Francés, J.; Navarro, V.; Pascual, I. Diffractive lenses recorded in absorbent photopolymers. Opt. Express 2016, 24, 1559-1572. [CrossRef] [PubMed]

26. Gallego, S.; Márquez, A.; Méndez, D.; Ortuño, M.; Neipp, C.; Fernández, E.; Pascual, I.; Beléndez, A. Analysis of PVA/AA based photopolymers at the zero spatial frequency limit using interferometric methods. Appl. Opt. 2008, 47, 2557-2563. [CrossRef] [PubMed]

27. Gallego, S.; Márquez, A.; Neipp, C.; Fernández, R.; Guardiola, J.M.; Francés, J.; Ortuño, M.; Pascual, I.; Beléndez, A. Model of low spatial frequency diffractive elements recorded in photopolymers during and after recording. Opt. Mater. 2014, 38, 46-52. [CrossRef]

28. Gallego, S.; Márquez, A.; Marini, S.; Fernández, E.; Ortuño, M.; Pascual, I. In dark analysis of PVA/AA materials at very low spatial frequencies: Phase modulation evolution and diffusion estimation. Opt. Express 2009, 17, 18279-18291. [CrossRef] [PubMed]

29. Goodman, J.W. Introduction to Fourier Optics, 3rd ed.; Roberts \& Company: Englewood, NJ, USA, 2005.

30. Hariharan, P. Optical Holography: Principles, Techniques, and Applications, 2nd ed.; Cambridge Studies in Modern Optics; Cambridge University: Cambridge, UK, 1996; p. 47.

31. Babeva, T.; Naydenova, I.; Martin, S.; Toal, V. Method for characterization of diffusion properties of photopolymerisable systems. Opt. Express 2008, 16, 8487-8497. [CrossRef] [PubMed]

32. Gallego, S.; Márquez, A.; Ortuño, M.; Marini, S.; Francés, J. High environmental compatibility photopolymers compared to PVA/AA based materials at zero spatial frequency limit. Opt. Mater. 2011, 33, 531-537. [CrossRef]

33. Cramer, N.B.; Bowman, C.N. Kinetics of thiol-ene and thiol-acrylate photopolymerizations with real-time fourier transform infrared. J. Polym. Sci. A Polym. Chem. 2001, 39, 3311-3319. [CrossRef]

34. Cramer, N.B.; Reddy, S.K.; O’Brien, A.K.; Bowman, C.N. Thiol-Ene Photopolymerization Mechanism and Rate Limiting Step Changes for Various Vinyl Functional Group Chemistries. Macromolecules 2003, 36, 7964-7969. [CrossRef]

35. Malallah, R.; Li, H.; Kelly, D.P.; Healy, J.J.; Sheridan, J.T. A Review of Hologram Storage and Self-Written Waveguides Formation in Photopolymer Media. Polymers 2017, 9, 337. [CrossRef]

36. Sabel, T.; Zschocher, M. Transition of refractive index contrast in course of grating growth. Sci. Rep. 2013, 3, 2552. [CrossRef] [PubMed]

(C) 2018 by the authors. Licensee MDPI, Basel, Switzerland. This article is an open access article distributed under the terms and conditions of the Creative Commons Attribution (CC BY) license (http://creativecommons.org/licenses/by/4.0/). 